\title{
Lovón Cueva, Marco Antonio (2020). Las palabras compuestas en la lengua aimara. Lima: Academia Peruana de la Lengua.
}

En los trabajos sobre la gramática de la lengua aimara, se ha dado mayor interés al estudio descriptivo, en especial, de la morfología flexiva y derivativa. Así, uno de los aspectos que no fue abordado con profundidad fue, hasta la aparición de esta publicación de Marco Lovón, la formación de palabras por composición. Sobre este tema, como bien lo señala nuestro autor, «se ha dudado de su existencia, sus estrategias, su tipología, y su productividad» (Lovón, 2020, p. 23). Sin embargo, en el Vocabulario aimara de 1612 ya se registra numerosísimas palabras compuestas como las siguientes: qillqa kamani 'escribiente' y aycha kamani 'carnicero' (< qillqa 'escritura' + kamani 'tener por oficio', aycha 'carne' + kamani 'idem', respectivamente), kayu nasa 'tibia' (< kayu 'pie' nasa 'nariz'), incluso formas «discutibles» como lakq'ara 'desdentado' (< laka 'boca' + q'ara 'sin nada') (Bertonio, 1612). Hasta el momento, solo algunos estudios hacen algunas referencias esporádicas sobre temas como la reduplicación (p.e., uta 'casa' $\rightarrow$ uta-uta 'caserío', qala 'piedra' $\rightarrow$ qala qala 'pedregal') y las llamadas contracciones vocálicas de corte transléxico (p.e., jichha 'ahora' + uru 'día' $\rightarrow$ jichhu:ru 'hoy', qhara 'antes' + uru 'día' $\rightarrow$ qharu:ru 'mañana') (cf. Cerrón-Palomino, 2008, p. 84, Hardman, Vásquez, Yapita et al., 2001, pp. 178-181, Adelaar, 2000, pp. 295-296, Huayhua, 2019, pp. 110-111).

El libro organizado en siete capítulos, que la Academia Peruana de la Lengua ha puesto en circulación, nos permite, finalmente, ponernos al día sobre la composición en el aimara y se fundamenta en el examen riguroso de datos provenientes del trabajo de campo en Conima (Puno), el Vocabulario de Ludovico Bertonio (1612) y otros vocabularios contemporáneos. En los dos primeros capítulos, el libro de Lovón presenta una explicación de la composición de las palabras como universal lingüístico y da énfasis a la explicación de los procedimientos morfológicos de derivación y, en especial, la composición de nuevos vocablos por ser el aimara una lengua aglutinante y fundamentalmente sufijante (Gonzalo, 2018). Y, enseguida, explica de manera panorámica y crítica esta estrategia de formar nuevas palabras en las lenguas andinas entre las extintas como la uro y la puquina, y contemporáneas como la chipaya, la quechua y la jaqaru, y nos sugiere que es también necesario estudiar el mecanismo de la composición en estas lenguas. 
Luego de darnos una referencia importante sobre la localización de la lengua, su historia y de presentarnos un esbozo lingüístico con énfasis en los aspectos fonológicos, sintácticos y morfológicos del aimara en el capítulo tercero, en el cuarto, nos ofrece una lista de criterios semánticos, fonológicos y sintácticos para identificar las palabras compuestas del aimara, que permite, en última instancia, distinguirlas de las frases. Así una palabra compuesta en cualquier lengua del mundo, considerando los dos primeros criterios propuestos en el texto, debe poseer un significado no-composicional (e.g. warmichuyma 'mujeriego' < warmi 'mujer' y chuyma 'corazón'), debe tener un significado unitario, constante y con un referente único (e.g. nasaphulu 'fosas nasales' < nasa 'nariz' y phulu 'hueco') y debe tener un único acento primario ([kaju'nasa] 'canilla' < kayu 'pie' y nasa 'nariz'). En lo que corresponde a los criterios sintácticos, se considera lo siguiente: la imposibilidad de extraer uno de los constituyentes, la imposibilidad de intercambiar la posición de los constituyentes, la imposibilidad de insertar elementos en el interior del compuesto y la imposibilidad de modificar uno de los constituyentes. La identificación de estos criterios ha permitido al autor formular la siguiente definición de palabra compuesta: «La palabra compuesta es una unidad sintáctica, fónica y con significado propio, que se distingue de los constituyentes que la componen» (Lovón, 2020, p. 136).

El quinto es el capítulo donde presenta el cotejo, examen y uso de los datos para la caracterización de las palabras compuestas en el aimara según su formación, su combinatoria sintáctica, su significado, así como la posición de su núcleo, la relación gramatical que implica, el tipo de motivación, ya sea semántica u onomatopéyica, y el número de piezas léxicas. Cabe señalar que, en este mismo capítulo, incidentalmente, se advierte de un caso especial que va «en contra» de la constitución sintáctica de un compuesto aimara tipo $[\mathrm{A}+\mathrm{N}]$, lengua en la que, como nos hace saber Lovón, los componentes A (adjetivo) modificador y N (nombre) núcleo van en ese orden y no a la inversa. En estas formaciones tipo [N+A], aparentemente extrañas en el aimara (e.g. nasa 'nariz' + jach'a 'grande' $\rightarrow$ nas (a) jach'a 'narizón', nayra 'ojos' + jisk'a 'pequeño' $\rightarrow$ nas (a) jisk'a 'el de ojos pequeños'), el A toma la posición nuclear, por tanto, en términos de la semántica composicional, es una función que debe ser saturada. Y, como dijimos arriba, estas expresiones ya fueron registradas por Bertonio en 1612, algo que no es común en el quechua y que el autor deja para una discusión futura.

En capítulo 6 se discute sobre las reduplicaciones como casos de composición y a estas se aplican los criterios de identificación señalados del cuarto capítulo. 
Ahí encontraremos los compuestos reduplicativos de forma (e.g. q'illu 'amarillo' $\rightarrow$ q'illuq'illu 'un arbusto amarillento'), de intensidad (e.g. k'aja 'tos' $\rightarrow$ k'ajak'aja 'tos convulsiva'), de cantidad (e.g. quqa árbol' $\rightarrow$ quqaquqa 'bosque'), de calidad (e.g. nina 'fuego' $\rightarrow$ ninanina 'luciérnaga'). Este capítulo lo ha formalizado, asimismo, en un artículo de reciente publicación (Lovón, 2021). Y, en el último capítulo del libro, se da cuenta sobre la alta productividad de la composición en la toponimia, la antroponimia, la fitonimia, zoonimia, en las danzas, el tiempo, los colores, las enfermedades, la anatomía, los números e, incluso, en los neologismos.

Para finalizar esta presentación, cabe advertir que los ejemplos se registran de acuerdo con el alfabeto aimara oficializado por la R.M N. ${ }^{\circ}$ 1218-85-ED, del 18 de noviembre de 1985 (cf. Anexo Nro. 1 del libro). Dicho sea de paso, este libro se deriva de la tesis de Maestría que Marco Lovón sustentó con mucho éxito en la Pontificia Universidad Católica del Perú en 2017, con la asesoría de Rodolfo Cerrón-Palomino, cuya lectura se recomienda a los lingüistas, a los profesores que trabajan en el área aimara, los aimaristas y el público con interés científico y pedagógico.

\section{Referencias bibliográficas}

Adelaar, W. \& Muysken, P. (2004). The Languages of the Andes. Cambridge: Cambridge University Press.

Bertonio, L. (1612). Vocabulario de la lengua aymara. Juli, Perú: Francisco del canto.

Cerrón-Palomino, Rodolfo (2008). Quechumara: estructuras paralelas del quechua y el aimara. Plural.

Gonzalo, R. (2018). Derivación de verbos de cambio en el aimara: -pta y -ra. Lengua y Sociedad, 17(2), 63-89. http://revista.letras.unmsm.edu.pe/index. $\mathrm{php} / \mathrm{ls} / \mathrm{article} / \mathrm{view} / 1094$

Hardman, M., Vásquez, J., Yapita, J.D., Briggs, L., England, N. \& Martin, L. (2001). Aymara: Compendio de estructura fonológica y gramatical. Segunda edición. Ediciones ILCA y Centro de Estudios Latino Americanos de la Universidad de Florida.

Huayhua, F. (2019). Gramática descriptiva de la lengua aimara (aymara aru yatiwi). Segunda edición. Moshera S. R. L.

Lovón, M. A. (2021). Compuestos reduplicados en el aimara. Atenea, (523), 11-38. https://doi.org/10.29393/AtAt523-408MLCR10408

460 Lengua y Sociedad. Revista de Lingüística Teórica y Aplicada 
Roger Gonzalo Segura Pontificia Universidad Católica del Perú, Lima-Perú rrgonzalo@pucp.pe https://orcid.org/oooo-0001-8072-0603

\section{Trayectoria académica}

Roger R. Gonzalo Segura, originario de Pomata, Puno, es licenciado en Educación: Lengua y Literatura por la Universidad Nacional del Altiplano de Puno (UnA-P) y magíster en Lingüística con mención en Estudios Andinos por la Pontificia Universidad Católica del Perú (PUCP). Actualmente, cursa los estudios de doctorado en Lingüística con la misma mención en la PUCP. Desde 2010, es docente de lenguas andinas en el Departamento de Humanidades de la PUCP y es docente visitante de la maestría de Lingüística Andina de la UNA-P. Su tesis magistral intitulada La derivación verbal en el aimara de Pomata fue una de las premiadas en el vir Concurso Nacional de Tesis de Postgrado-2013, organizado por la desaparecida Asamblea Nacional de Rectores del Perú. Entre sus publicaciones destaca la traducción al aimara de la novela corta El Principito de Antonie De Saint-Exupéry con el título de Pirinsipi wawa en 2015, el Manual de escritura aimara - aymara arutha chiqapa qillqañataki panka (2017) y la versión castellana publicada en 2021. 